\title{
Outcome Evaluation of Fistula Care Project in Bench Sheko Zone, Southern Nations Nationalities, and Peoples' Region, Ethiopia, 2020
}

\author{
Zerihun Asefa ${ }^{1 *}$, Demisew Amenu ${ }^{1}$, Aster Berhe ${ }^{2}$, Muluneh Getachew ${ }^{3}$ and Feyissa Tolessa ${ }^{3}$ \\ ${ }^{1}$ Department of Obstetrics and Gynecology, Jimma University, Ethiopia \\ ${ }^{2}$ United Nation Population Fund, Addis Ababa, Ethiopia \\ ${ }^{3}$ Department of Health Policy and Management, Jimma University, Ethiopia

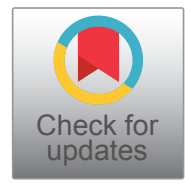

*Corresponding author: Zerihun Asefa, Department of Obstetrics and Gynecology, Jimma University, Ethiopia

\begin{abstract}
Background: Obstetric fistula is the most severe of pregnancy-related disabilities. While the condition has disappeared in developed countries, it remains a source of concern in Ethiopia and serves as a proxy indicator of the status of Ethiopian women and the availability and access to quality maternal health services. However, to our best knowledge, there was no evidence of the outcome of the fistula care project in the study setting. Therefore, this study aimed to evaluate the outcome of the fistula care project on women's knowledge in Bench Sheko Zone, Ethiopia 2020.
\end{abstract}

Methods: Quasi-experimental design with comparison groups post-test only was employed in Semen Bench as an intervention and Guraferda Woreda as a comparison group of Bench sheko Zone from February 15, 2020 to March 15, 2020. A multi-stage sampling technique was employed to select 284 women for intervention and 284 comparison group. The focus of this evaluation was the intermediate outcome of the fistula care project. Data were managed by using Kobo Collect v1.25.1 and Descriptive frequency, Bivariate, and Multivariate regression analyses were performed to examine the effects of intervention exposure by using Stata version 16.0.

Result: Women's knowledge of obstetric fistula causes, risk, symptoms, and prevention shows that the intervention group has a significant difference when compared with the counterpart $(p<0.001)$. Overall knowledge of obstetric fistula was $69.7 \%$ and $30.4 \%$ have good knowledge towards obstetric fistula from intervention and comparison group respectively $(p<0.001)$. Knowledge about obstetric fistula was higher among respondent's who can read \& write (AOR $=2.707: 95 \% \mathrm{Cl}(1.433-5.686))$, primary level of education $(A O R=2.073: 95 \% \mathrm{Cl}(1.266-3.395))$, Secondary school and above education $(\mathrm{AOR}=2.822: 95 \% \mathrm{Cl}(1.338-5.952))$ than women who have no formal education. Similarly, heard about obstetric complications (AOR $=4.478: 95 \% \mathrm{Cl}(2.635-$ $7.610)$ ), history of induced abortion(AOR $=2.347: 95 \% \mathrm{Cl}$ (1.203-4.576)), intervention woreda $(A O R=2.707: 95 \% \mathrm{Cl}$ (1.771-4.138)) attending pregnant women conference (AOR $=0.06: 95 \% \mathrm{Cl}(0.02-0.19))$, > greater than 20 years age at first pregnancy $(\mathrm{AOR}=1.7295 \% \mathrm{Cl}(1.10-2.68)$ ) were the factors associated with knowledge of obstetric fistula.

Conclusion and recommendation: Findings from this outcome evaluation shows that there are measurable differences between intervention and comparison woreda in terms of women's knowledge of obstetric fistula Cause, risk, symptom, prevention, and treatment of obstetric fistula. Also, significant differences were observed in the overall knowledge of obstetric fistula in the intervention area than the counterpart. Therefore, Community based intervention can increase women's knowledge and encourage the use of essential obstetric services.

\section{Keywords}

Obstetric fistula, Outcome evaluation, Knowledge level, Women, Bench sheko zone, Ethiopia
Abbreviations
EmOC: Emergency Obstetric Care; HFE: Hamlin Fistula Ethiopia; OF: Obstetric Fistula; UNFPA: United Nations Population Fund; USAID: United States Agency for International Development; VVF: Vesico Vaginal Fistula; WAHA: Women and Health Alliance; WHO: World Health Organization

Citation: Asefa Z, Amenu D, Berhe A, Getachew M, Tolessa F (2021) Outcome Evaluation of Fistula Care Project in Bench Sheko Zone, Southern Nations Nationalities, and Peoples' Region, Ethiopia, 2020. Int J Womens Health Wellness 7:129. doi.org/10.23937/2474-1353/1510129

Accepted: December 02, 2021: Published: December 04, 2021

Copyright: (C) 2021 Asefa Z, et al. This is an open-access article distributed under the terms of the Creative Commons Attribution License, which permits unrestricted use, distribution, and reproduction in any medium, provided the original author and source are credited. 


\section{Background}

Obstetric fistula is one of the most genuine and disastrous childbirth injuries. An opening between the birth canal, and bladder, and/or additionally rectum is caused by prolonged, obstructed labor without access to timely, quality medical treatment. It leaves women leaking urine, feces, or both and often leads to chronic medical problems, depression, social isolation, and poverty. It leaves women leaking urine, feces, or both, and often leads to chronic medical problems [1].

According to the World Health Organization (WHO), obstetric fistula prevention strategies include delaying the age of first pregnancy; the cessation of harmful traditional practices; and timely access to obstetric care. Preventing and managing obstetric fistula contribute to the Sustainable Development Goal 3 of improving maternal health [2].

The wide spread outbreak of fistula in 1857 lead to the construction of the world's first hospital, known as New York's Women's Hospital. Economic development and healthcare improvements subsequently drastically reduced the rate of obstetric accidents in the United State. Moreover, while fistula has long been known to be both preventable and often treatable in the West, this disorder still affects many young women in the developing world, a situation that speaks to problems with both economic resources and healthcare services and especially in maternal healthcare. But increased access to sufficient antenatal and emergency obstetric care would allow more women to avoid days of obstructed labor that can often lead to fistula [3].

The World Health Organization (WHO) estimates that over $\mathbf{3 0 0}$ million women currently suffer from short or long-term complications arising from pregnancy or childbirth, with around 20 million new cases arising every year worldwide. Problems include infertility, severe anemia, uterine prolapse, and vaginal fistula. It estimates that about 50,000-100,000 women develop obstetric fistula annually with at least 33,000 of these located in sub-Saharan Africa [2].

Obstetric fistula is found in developing countries. However, the majority of obstetric fistula are confined to the "fistula belt" across the northern half of subSaharan Africa from Mauritania to Eritrea and in the developing countries of Middle East Asia [4]. Obstetric fistula is the major public health problem of health in Ethiopia. While the condition has disappeared in developed countries, it remains a source of concern in Ethiopia and serves as proxy indicators of the status of Ethiopian women and the availability and access to quality maternal health services.

Obstetric fistula is the most severe devastating morbidity of pregnancy and childbirth. It primarily affects young, poor women whose families lack the means to access quality maternal care. Many of these women remain hidden in remote villages. Even those who have access to surgical repair face long waits, as the demand is far greater than the capacity of existing facilities. In many areas, repair services simply do not exist [5].

USAID 2013 analysis of the problem estimated that there are between 36,000 to 39,000 women currently living with obstetric fistula and that between 3,300 and 3,750 new obstetric fistula cases occur in Ethiopia every year. Because of the low rate of institutional deliveries, data on birth outcomes is not yet universally or routinely available in Ethiopia, so this data was generated through modeled estimates [6]. Many barriers to fistula treatment, which operate at the individual, community, and national levels. The successful treatment of obstetric fistula may thus require targeting several barriers, including depression, stigma, and shame, lack of community-based referral mechanisms, the financial cost of the procedure, transportation difficulties, gender power imbalances, the availability of facilities that offer fistula repair, community reintegration and the competing priorities of political leadership. Perhaps one of the most difficult barriers is a lack of knowledge of fistula [7].

Even though Ethiopia launched a five-year program on obstetric fistula elimination in 2014 under the theme "Ending obstetric fistula and Transforming Lives by 2020 ". The Federal Ministry of Health is leading the development of an action plan to speed up the elimination of obstetric fistula by the year 2020 [8].

The Jimma University Fistula Care Project, as an implementing partner has worked on the prevention and treatment of obstetric fistula for the past seven years by training health workers and communities' key leaders in efforts to increase knowledge about the prevention of obstetric fistula. This knowledge is used in strengthening preventive techniques towards obstetric fistula both at the health facility and the community level. The present study is, therefore, aimed at the outcome of the fistula care project on the knowledge of the women on obstetric fistula and its associated factors.

\section{Methods}

\section{Study area}

The evaluation was conducted in Semen Bench and Guraferda Woreda of Bench Sheko zone of southern Nations Nationalities and Peoples Region, Ethiopia between February and March 2020. Outcome evaluation of the fistula care project was conducted using a quasiexperimental design with comparison groups post-test only. Intervention areas were purposively sampled to focus on kebele in each woreda that had exposure to the intervention. A classic method for supporting a counterfactual inference is to add a comparison group that received no intervention, with the comparison group 
selected to be as similar as possible to the intervention group. Indicators were selected by referring to the 2015 strategic plan [8], WHO Guideline [9]. Finally, 22 indicators were selected.

\section{Sample size determination and sampling technique}

The sample size was calculated using two population proportions formula by using G-power v3.1 software with the following the assumption [10]: Difference between two independent proportions by one to one allocation ration and $80 \%$ power was used to detect a $15 \%$ difference in the proportion of women with knowledge of obstetric fistula. Then after considering a $5 \%$ non-response rate and 2 design effects the final sample size was 564 ( 282 from intervention and 282 from comparison group). A multi-stage sampling technique was employed. In the first stage for both groups, 30\% of kebeles were selected by a simple random sampling technique. The sample size was proportionally allocated for each kebeles.

\section{Data collection tools}

A structured questioner was adapted from previously conducted studies in Eritrea, Guinea, Awi zone, North West, Ethiopia. For the sociodemographic and knowledge part of the study question [11-13]. The questionnaire includes three parts background information, Obstetric information, and, questions on obstetric fistula. Knowledge of obstetric fistula was assessed by evaluating responses to 22 questions on obstetric fistula including the cause, risk factors, symptoms, prevention method, and treatment of obstetric fistula.

Data Collectors for the evaluation were B.Sc. health professionals outside the study area to minimize bias. Data collectors and supervisors were trained for two days to be familiar with all types of data, tools, and data collection methods and objectives. And one-day practical sessions on Kobo Collect. The data collection method was done through face to face interviews by using Kobo collect. Female house head was primary respondents and in the absence of them, Females age greater than 18 were interviewed. If both not present at the time of data collection revisit at least two times.

\section{Intervention}

Intervention training was given to key community leaders as maternal health volunteers. Key community leaders include kebele manager, religious leaders, health extensions workers, school director, HDAs, Kebele Women and children affairs, woreda Women and children affairs, zone Women and children affairs, and health providers, woreda $\mathrm{MCH}$ Head, health center $\mathrm{MCH}$ focal person were trained at woreda level for 2 days.

The key elements of the intervention were increasing obstetric fistula identification, prevention, and treatment through women participation in pregnant women conferences, educating pregnant women and their husbands, and key community during home visits on early and complete ANC visits.

\section{Data quality control}

The data collection tool was translated into Amharic language and translated back to English to check its consistency. A pre-test was done on $5 \%$ of participants at Sheko woreda and some modifications were made in the final version of the questionnaire. During data collection, completeness and consistency of information including typing errors were checked by the supervisor and principal evaluator daily. In this study, the reliability of knowledge measuring items was checked by calculating the Cronbach alpha $(\alpha)$. The Cronbach alpha was inter-item consistency (Cronbach alpha) for knowledge measuring tools of 22 items was 0.76. In light of the above-mentioned Cronbach's Alpha values, the measuring instrument is deemed reliable for both intervention and comparison groups.

\section{Data processing and analysis}

All data were electronically collected on-site and uploaded daily to the kobo server database using kobo collect v1.25.1(kobotoolbox.org). Database content was checked for missing answers, duplications, and inconsistencies. Then data were then exported to Stata software version 16.0 for further analysis.

Descriptive statistics were used to determine the frequency, mean, and proportions of variables. A p-value of $<0.05$ was considered statically significant. In bivariate logistics regression, a variable whose $p<$ 0.25 was considered as a candidate for multivariable logistic regression analysis. And variables having $p<$ 0.05 after multivariable logistic regression analysis were considered as independent predictors for knowledge. The backward elimination method was done to fit the final model. Statistical significance was assessed using the chi-square test, odds ratios, and $95 \% \mathrm{Cl}, \mathrm{p}$ values less than 0.05 used as cut off point for Statistical significance. Hosmer-Lemeshow goodness of fit was used to check the goodness of the applied models (0.48) and the model adequately fits the data.

\section{Operational definitions}

Knowledge was measured by 22 items. Mean was calculated to categorize into two. Those who scored above the mean were considered as good knowledge, and those who scored below the mean were considered as poor knowledge. Those women who define obstetric fistula by describing at least one way were taken as know the definition of obstetric fistula. Those women who least at least one cause of obstetric fistula was taken as know the cause of obstetric fistula. Those women who least at least two risk factors of obstetric fistula were taken as know risk of obstetric fistula. Those women 
who least at least two symptoms of obstetric fistula were taken as know the symptoms of obstetric fistula. Those women who least at two prevention methods of obstetric fistula were taken as know the prevention method of obstetric fistula. Those women who answer at least two questions about obstetric fistula were taken as know obstetric fistula will be treated.

\section{Results}

\section{Sociodemographic characteristics of study participants}

Five hundred eighteen women (259 respondents from the intervention $\& 259$ respondents from control groups) have participated in the study with a response rate of $91.8 \%$. The mean age of participants was 32.0 and 30.9 (SD+ 9.8 vs. 8.5) years-old for the intervention and comparison group respectively. And the mean age at marriage was 20.5 vs 19.2 years in the intervention and comparison group. One-hundred five (40.5\%) and 155(59.8\%) had not attended formal education among intervention and comparison groups respectively. More women in the comparison area were no formal education ( $59.8 \%$ vs. $40.5 \%), p<0.001$. similarly, more Husband of women in the comparison group are farmers and have no formal education $p<0.001$. on the other hand, more women in the intervention group have distance from the nearest Health facility $>30$ minutes compared to the comparison group $(95.8 \%$ vs. $88.4 \%) \mathrm{P}<0.001$. Given these differences, we adjusted for women's Educational status, Husband Occupational Status, and Husband Educational Status in the final analyses. And other socio-demographic variables were similar in both groups (Table 1 ).

\section{Obstetric factors}

The proportion of women who heard about obstetric complications was 197 (76.1\%) in the intervention group compared to 146 (56.4\%) in the comparison group. About twenty-seven (10.4\%) and 22 (8.5\%) of the women have a history of induced abortion from intervention and comparison groups respectively. Levels of birth preparedness and complication readiness were 188 (72.6\%) and 111 (42.9\%) in the intervention and comparison group respectively. Knowledge about obstetric complication, family planning, ANC use, the benefits of Institutional delivery, a danger sign, Birth preparedness, and complication readinessis higher in the intervention group compared to the comparison group, $P<0.001$. The other Characteristics of respondents

Table 1: Socio-demographic characteristics of participants $(n=518)$.

\begin{tabular}{|c|c|c|c|c|}
\hline \multicolumn{2}{|l|}{ Variables } & \multirow{2}{*}{\begin{tabular}{|l} 
Intervention group \\
(n = 259) (n= \%) \\
$3(0.4 \%)$
\end{tabular}} & \multirow{2}{*}{$\begin{array}{l}\text { Comparison group } \\
\text { (n = 259) (n= \%) } \\
6(2.3 \%)\end{array}$} & \multirow{2}{*}{\begin{tabular}{|l|} 
p-value \\
0.222 \\
\end{tabular}} \\
\hline Age group & $15-19$ & & & \\
\hline & $20-24$ & $43(8.3 \%)$ & $48(18.5 \%)$ & \\
\hline & $25-29$ & $70(27 \%)$ & $62(23.9 \%)$ & \\
\hline & $30-34$ & $54(20 \%)$ & $63(24.3 \%)$ & \\
\hline & $35-39$ & $47(18.1 \%)$ & $54(20.8 \%)$ & \\
\hline & $40-44$ & $10(3.9 \%)$ & $11(4.2 \%)$ & \\
\hline & $45-49$ & $8(3.1 \%)$ & $5(1.9 \%)$ & \\
\hline & $>49$ & $24(9.3 \%)$ & $10(3.9 \%)$ & \\
\hline \multirow[t]{4}{*}{ Religion } & Orthodox & $60(23.2 \%)$ & $134(51.7 \%)$ & $<0.001$ \\
\hline & Protestant & $186(71.8 \%)$ & $71(27.4 \%)$ & \\
\hline & Muslim & $2(0.8 \%)$ & $38(14.7 \%)$ & \\
\hline & Catholic & $11(4.2 \%)$ & $16(6.2 \%)$ & \\
\hline \multirow[t]{4}{*}{ Marital status } & Married & $249(96.1 \%)$ & $242(93.4 \%)$ & 0.178 \\
\hline & Single & $7(2.7 \%)$ & $8(3.1 \%)$ & \\
\hline & Divorced & $1(0.4 \%)$ & $8(3 \%)$ & \\
\hline & Widowed & $2(0.8)$ & $1(0.4 \%)$ & \\
\hline \multirow[t]{4}{*}{ Occupational Status } & House Wife & $212(81.9 \%)$ & $225(86.7 \%)$ & 0.047 \\
\hline & Employed & $20(7.7 \%)$ & $12(4.6 \%)$ & \\
\hline & Marchant & $19(7.3 \%)$ & $21(8.1 \%)$ & \\
\hline & Student & $8(3.1 \%)$ & $1(0.4 \%)$ & \\
\hline \multirow[t]{4}{*}{ Educational status } & No formal education & $105(40.5 \%)$ & $155(59.8 \%)$ & $<0.001$ \\
\hline & Read \& write only & $31(12 \%)$ & $22(8.5 \%)$ & \\
\hline & Primary School & $67(25.9 \%)$ & $91(35.1 \%)$ & \\
\hline & Secondary school and Above & $32(12.4 \%)$ & $15(5.8 \%)$ & \\
\hline
\end{tabular}




\begin{tabular}{|l|l|l|l|}
\hline Age at first pregnancy & $<20$ years & $151(58.3 \%)$ & $169(65.3 \%)$ \\
\hline & $>20$ Years & $101(39.0 \%)$ & $82(31.7 \%)$ \\
\hline Husband Occupational Status & Farmer & $199(76.8 \%)$ & $220(84.9 \%)$ \\
\hline & Employed & $34(13.1 \%)$ & $16(6.2 \%)$ \\
\hline & Marchant & $19(7.3 \%)$ & $23(8.9 \%)$ \\
\hline & Student & $7(2.7 \%)$ & $0(0 \%)$ \\
\hline Husband Educational Status & No formal education & $77(29.7 \%)$ & $143(55.2 \%)$ \\
\hline & Read \& write only & $32(12.4 \%)$ & $47(18.1 \%)$ \\
\hline & Primary education & $97(37.5 \%)$ & $45(17.4 \%)$ \\
\hline $\begin{array}{l}\text { Distance from the nearest } \\
\text { Health facility }\end{array}$ & Secondary school and above & $53(20.5 \%)$ & $24(9.3 \%)$ \\
\hline & $<30$ Minutes & $11(4.2 \%)$ & $30(11.6 \%)$ \\
\hline
\end{tabular}

Chi-square test, $p<0.05$ is statistically significant.

Table 2: Characteristics of respondents about obstetrical factors $(n=518)$.

\begin{tabular}{|c|c|c|c|c|}
\hline \multicolumn{2}{|l|}{ Variables } & \multirow{2}{*}{$\begin{array}{l}\text { Intervention group } \\
\text { (n=259) (n=\%) } \\
62(23.9 \%)\end{array}$} & \multirow{2}{*}{$\begin{array}{l}\text { comparison group } \\
\text { (n= 259) }(n=\%) \\
113(43.6 \%)\end{array}$} & \multirow{2}{*}{$\begin{array}{l}\text { p-value } \\
<0.001\end{array}$} \\
\hline Heard about obstetric & No & & & \\
\hline & Yes & $197(76.1 \%)$ & $146(56.4 \%)$ & \\
\hline \multirow[t]{2}{*}{ History of induced abortion } & No & $232(89.6 \%)$ & $237(91.5 \%)$ & 0.885 \\
\hline & Yes & 27 (10.4\%) & $22(8.5 \%)$ & \\
\hline \multirow{2}{*}{$\begin{array}{l}\text { History of Birth related } \\
\text { complication }\end{array}$} & No & $229(88.4 \%)$ & $230(88.8 \%)$ & 0.787 \\
\hline & Yes & $30(11.6 \%)$ & $29(11.2 \%)$ & \\
\hline \multirow[t]{2}{*}{ Ever use family planning } & No & $49(18.9 \%)$ & $80(30.9 \%)$ & 0.001 \\
\hline & Yes & $210(81.2 \%)$ & $179(69.1 \%)$ & \\
\hline \multirow[t]{3}{*}{ Number of Delivery } & $<1$ & $43(16.6 \%)$ & $50(19.3 \%)$ & 0.010 \\
\hline & $1-2$ & $164(63.3 \%)$ & $179(69.1 \%)$ & \\
\hline & $>5$ & $45(17.4 \%)$ & $22(8.5 \%)$ & \\
\hline \multirow[t]{3}{*}{ Number of Pregnancy } & $<=1$ & $49(18.9 \%)$ & $58(22.4 \%)$ & 0.320 \\
\hline & $2-5$ & $172(66.4 \%)$ & $175(67.6 \%)$ & \\
\hline & $>5$ & $38(14.7 \%)$ & $26(10 \%)$ & \\
\hline \multirow[t]{2}{*}{ Know the benefit of ANC } & No & $81(31.3 \%)$ & $99(38.2 \%)$ & 0.016 \\
\hline & Yes & $178(68.7 \%)$ & $160(61.8 \%)$ & \\
\hline \multirow{2}{*}{$\begin{array}{l}\text { Know the benefits of Institutional } \\
\text { delivery }\end{array}$} & No & $69(26.6 \%)$ & $148(57.1 \%)$ & $<0.001$ \\
\hline & Yes & $190(73.4 \%)$ & $111(42.9 \%)$ & \\
\hline \multirow[t]{2}{*}{ Know danger sign } & No & $67(25.9 \%)$ & $117(45.2 \%)$ & $<0.001$ \\
\hline & Yes & $192(74.1 \%)$ & $142(54.8 \%)$ & \\
\hline \multirow{3}{*}{$\begin{array}{l}\text { know Birth preparedness and } \\
\text { complication read ness }\end{array}$} & No & $71(27.4 \%)$ & $148(57.1 \%)$ & $<0.001$ \\
\hline & Yes & $188(72.6 \%)$ & $111(42.9 \%)$ & \\
\hline & 0 & $9(3.5 \%)$ & $11(4.3 \%)$ & 0.047 \\
\hline \multirow[t]{3}{*}{ Number of Children } & $1-2$ & $94(36.3 \%)$ & $112(43.3 \%)$ & \\
\hline & $3-4$ & $92(35.5 \%)$ & $97(37.5 \%)$ & \\
\hline & $>=5$ & $64(24.7 \%)$ & $39(15.1 \%)$ & \\
\hline \multirow[t]{2}{*}{ Place of delivery } & Home & $62(25.4 \%)$ & $114(47.1 \%)$ & $<0.001$ \\
\hline & $\begin{array}{l}\text { Health } \\
\text { Facility }\end{array}$ & $182(74.6 \%)$ & $128(52.9 \%)$ & \\
\hline
\end{tabular}

Chi-square test, $p<0.05$ is statistically significant. 
about obstetrical factors were similar in both groups (Table 2).

\section{Knowledge of obstetric fistula}

Concerning knowledge related to obstetric fistula percentages of women who reported that they had heard of obstetric fistula were 140 (54\%) in the intervention group and able to describe what obstetric fistula is, compared with 53 (20.5\%) of women in the comparison group. And the difference was statistically significant at $p$-value $<0.001$. Among those who had heard of obstetric fistula, the most commonly cited sources of information about fistula were health extension workers (63.7\%) with P-value $<0.001$, Media
$(23.8 \%)$, Family \& friend $(28.5 \%)$, and women who had been treated for fistula (4.7\%).

One hundred twenty-three (49.4\%) of those in the intervention group were able to list at least one cause of the obstetric fistula, compared with $18.4 \%$ in comparison woreda. And the difference is statistically significant at p-value $<0.001$. As shown in Table 3 below 106 (75.7\%) of the respondents replayed that prolonged labor as cause and 81 (57.9\%) sexual violence as a cause from the intervention group, and the comparison group 43 $(64.2 \%)$ and $29(43.3 \%)$ of the respondents prolonged and sexual violence as a cause respectively.

Regarding knowledge of obstetric fistula, the

Table 3: Participants' characteristics of knowledge on obstetric fistula causes, risk factors, and symptoms.

\begin{tabular}{|c|c|c|c|c|}
\hline \multicolumn{2}{|l|}{ Obstetric fistula indicators } & $\begin{array}{l}\text { Intervention group } \\
(n=140)(n=\%)\end{array}$ & $\begin{array}{l}\text { Comparison group } \\
(n=67)(n=\%)\end{array}$ & p-value \\
\hline \multicolumn{2}{|l|}{ Ever heard obstetric fistula } & $140(54.1)$ & $67(25.9)$ & $<0.001$ \\
\hline \multicolumn{5}{|l|}{ How to describe obstetric fistula } \\
\hline \multicolumn{2}{|l|}{ Continuous leakage of urine } & $114(81.4)$ & $40(59.7)$ & 0.001 \\
\hline \multicolumn{2}{|c|}{ Continuous leakage of urine and or feces } & $17(12)$ & $23(34.3)$ & \\
\hline \multicolumn{2}{|l|}{ The continuous odor of urine } & $9(6.4)$ & $4(6)$ & \\
\hline \multicolumn{2}{|l|}{ Describe obstetric fistula } & $140(54.1)$ & $63(24.3)$ & $<0.001$ \\
\hline \multicolumn{5}{|l|}{ Source of information } \\
\hline \multicolumn{2}{|l|}{ Health extension worker } & $123(63.7)$ & $34(17.6)$ & 0.004 \\
\hline \multicolumn{2}{|l|}{ Family and friend } & $55(28.5)$ & $22(11.4)$ & 0.079 \\
\hline \multicolumn{2}{|l|}{ School } & $15(7.8)$ & $7(3.6)$ & 0.568 \\
\hline \multicolumn{2}{|l|}{ Media } & $46(23.8)$ & $5(2.6)$ & 0.076 \\
\hline \multicolumn{5}{|l|}{ Causes ofobstetric fistula } \\
\hline \multirow{2}{*}{$\begin{array}{l}\text { Knows prolonged labor as a cause } \\
\text { of fistula }\end{array}$} & No & $34(24.3)$ & $24(35.8)$ & 0.084 \\
\hline & Yes & $106(75.7)$ & $43(64.2)$ & \\
\hline \multirow{2}{*}{$\begin{array}{l}\text { Knows sexual violence as a cause } \\
\text { of fistula }\end{array}$} & No & $59(42.1)$ & $38(56.7)$ & 0.049 \\
\hline & Yes & $81(57.9)$ & $29(43.3)$ & \\
\hline \multirow{2}{*}{$\begin{array}{l}\text { Know at least one cause } \\
(n=259)\end{array}$} & No & $136(52.5)$ & $211(81.5)$ & 0.000 \\
\hline & Yes & $123(49.5)$ & $48(18.5)$ & \\
\hline \multirow[t]{5}{*}{ Risk of factors } & Early Marriage & $87(62.1 \%)$ & $35(52.2 \%)$ & 0.175 \\
\hline & Early Pregnancy & $60(42.9 \%)$ & $38(56.7 \%)$ & 0.062 \\
\hline & Home delivery & $111(79.3 \%)$ & $31(46.3 \%)$ & $<0.001$ \\
\hline & Female Genital cutting & $45(32.1 \%)$ & $8(11.9 \%)$ & 0.002 \\
\hline & Prolonged labor & $22(15.7 \%)$ & $3(4.5 \%)$ & 0.020 \\
\hline \multirow{2}{*}{$\begin{array}{l}\text { Know at least two Risk factors } \\
(\mathrm{n}=259)\end{array}$} & No & $139(53.7)$ & $220(84.9)$ & $<0.001$ \\
\hline & Yes & $120(46.3)$ & $39(15.1)$ & \\
\hline \multirow[t]{4}{*}{ Symptoms } & Unable to control urine & $131(93.6)$ & $57(85.1)$ & 0.048 \\
\hline & Unable to control feces & $122(87.1)$ & $32(47.8)$ & 0.018 \\
\hline & Unable to control urine and feces & $85(60.7)$ & $29(43.3)$ & 0.048 \\
\hline & Bleeding and pain during sex & $9(3.5)$ & $10(14.9)$ & 0.005 \\
\hline \multirow{2}{*}{$\begin{array}{l}\text { Know at least two symptoms } \\
(n=259)\end{array}$} & No & $130(50.2)$ & $224(86.5)$ & 0.000 \\
\hline & Yes & $129(49.8)$ & $35(13.5)$ & \\
\hline
\end{tabular}

Chi-square test, $p<0.05$ is statistically significant 
proportion of women who perceive at least two or more risk factors of the obstetric fistula was 139 (53.7\%) versus $43(16.6 \%)$ of the intervention group and a comparison group respectively. The difference is statistically significant at $p$-value $<0.001$. concerning the knowledge on the risk of obstetric fistula, a high proportion of women in the intervention group perceived risk factors for obstetric fistula includes home delivery 111 (79.3\%) and Early Marriage 87 (62.1\%).

Regarding the symptoms of Obstetric fistula, women who can cite 2 or more symptoms of obstetric fistula were $140(54.1 \%)$ in the intervention group compared to $53(20.5 \%)$ in the comparison group. This difference is statistically significant at $p$-value $<0.001$. Knowledge of the women in the intervention group is higher on symptoms of unable to control urine (37\% vs. $13 \%$ ), unable to control feces ( $36 \%$ vs. $3.5 \%)$, and unable to control urine and feces ( $32.8 \%$ vs. $6 \%$ ) compared to the comparison group (Table 3 ).

\section{Knowledge of obstetric fistula prevention method and treatment}

Concerning obstetric fistula prevention, 135 (52.1\%) versus $35(18.9 \%)$ of participants were able to cite 1 or more ways to prevent fistula from the intervention and the comparison group. And the difference is statistically significant at $p$-value $<0.001$. From obstetric fistula prevention methods, the intervention group was list delivery with a skilled birth attendant 77 (55\%) and
Health Facility Delivery 71 (50.7\%). This outcome evaluation shows that the proportion of women who know that obstetric fistula can be treated are 124 (47.9\%) from the intervention group and 38 (14.7\%) in the comparison group. The difference is statistically significant at $\mathrm{p}$-value $<0.001$. similarly, 69 (49.3\%) versus 27 (40.3\%) respondents have fistula repair center information from intervention and comparison group respectively (Table 4).

\section{Overall knowledge status of women on obstetric fistula}

According to this outcome evaluation, the overall knowledge status of women on obstetric fistula was $140(69.7 \%)$ and 61 (30.4\%) were good knowledge and 119 (37.5\%) and 198 (62.5\%) were poor knowledge for intervention and comparison group respectively. And the overall knowledge status of women difference between intervention and comparison is statistically significant at $\mathrm{p}$-value $<0.001$ (Figure 1).

\section{Determinants of women'sknowledge on obstetric fistula}

The bivariate analysis result shows that educational status of women, age at first pregnancy, obstetric complication, history of induced abortion, modern contraceptive use, ANC for last pregnancy, know benefits of institutional delivery, know danger sign during pregnancy and childbirth, know birth preparedness and

Table 4: Participants' characteristics of knowledgeon prevention\& treatment of obstetric fistula $(n=518)$.

\begin{tabular}{|c|c|c|c|c|c|}
\hline \multicolumn{3}{|c|}{ Indicators } & \multirow{2}{*}{ 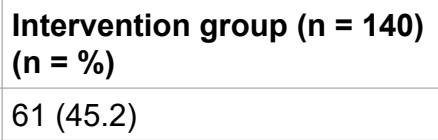 } & \multirow{2}{*}{$\begin{array}{l}\begin{array}{l}\text { Comparison group }(n=67) \\
(n=\%)\end{array} \\
10(28.6)\end{array}$} & \multirow{2}{*}{$\begin{array}{l}\text { p-value } \\
0.002\end{array}$} \\
\hline \multirow{12}{*}{ 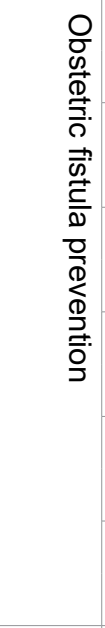 } & \multirow[t]{2}{*}{ Delaying the age of early marriage } & No & & & \\
\hline & & Yes & $74(54.8)$ & $39(79.6)$ & \\
\hline & \multirow[t]{2}{*}{ Cessation of Early pregnancy } & No & $51(37.8)$ & $26(74.3)$ & 0.000 \\
\hline & & Yes & $84(62.2)$ & $15(30.6)$ & \\
\hline & \multirow[t]{2}{*}{ Timely access to the health facility } & No & $96(71.1)$ & $27(77.1)$ & 0.041 \\
\hline & & Yes & $39(28.9)$ & $22(44.9)$ & \\
\hline & \multirow{2}{*}{$\begin{array}{l}\text { Delivery with a skilled birth } \\
\text { attendant }\end{array}$} & No & $63(45)$ & $38(71.7)$ & 0.000 \\
\hline & & Yes & $77(50)$ & $18(26.9)$ & \\
\hline & \multirow[t]{2}{*}{ Health Facility Delivery } & No & $69(49.3)$ & $34(64.2)$ & 0.005 \\
\hline & & Yes & $71(50.7)$ & $20(29.9)$ & \\
\hline & \multirow{2}{*}{$\begin{array}{l}\text { Know at least one prevention } \\
\text { method }(n=259)\end{array}$} & No & $124(47.9)$ & $210(81.1)$ & 0.000 \\
\hline & & Yes & $135(52.1)$ & $49(18.9)$ & \\
\hline \multirow{8}{*}{ 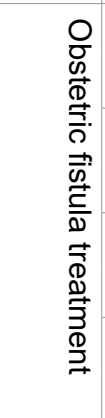 } & \multirow[t]{2}{*}{ Know OF will be treated } & No & $14(10)$ & $26(38.8)$ & $<0.001$ \\
\hline & & Yes & $126(90.0)$ & $41(61.2)$ & \\
\hline & \multirow[t]{2}{*}{ Know cured OF women } & No & $115(82.1)$ & $53(79.1)$ & 0.601 \\
\hline & & Yes & $25(17.9)$ & $14(20.9)$ & \\
\hline & \multirow[t]{2}{*}{ Know fistula repair center } & No & $71(50.7)$ & $40(59.7)$ & 0.225 \\
\hline & & Yes & $69(49.3)$ & $27(40.3)$ & \\
\hline & \multirow{2}{*}{$\begin{array}{l}\text { Answer at least two treatment- } \\
\text { related }\end{array}$} & No & $135(52.1)$ & $221(85.3)$ & \\
\hline & & Yes & $124(47.9)$ & $38(14.7)$ & $<0.001$ \\
\hline
\end{tabular}

Chi-square test, $p<0.05$ is statistically significant. 


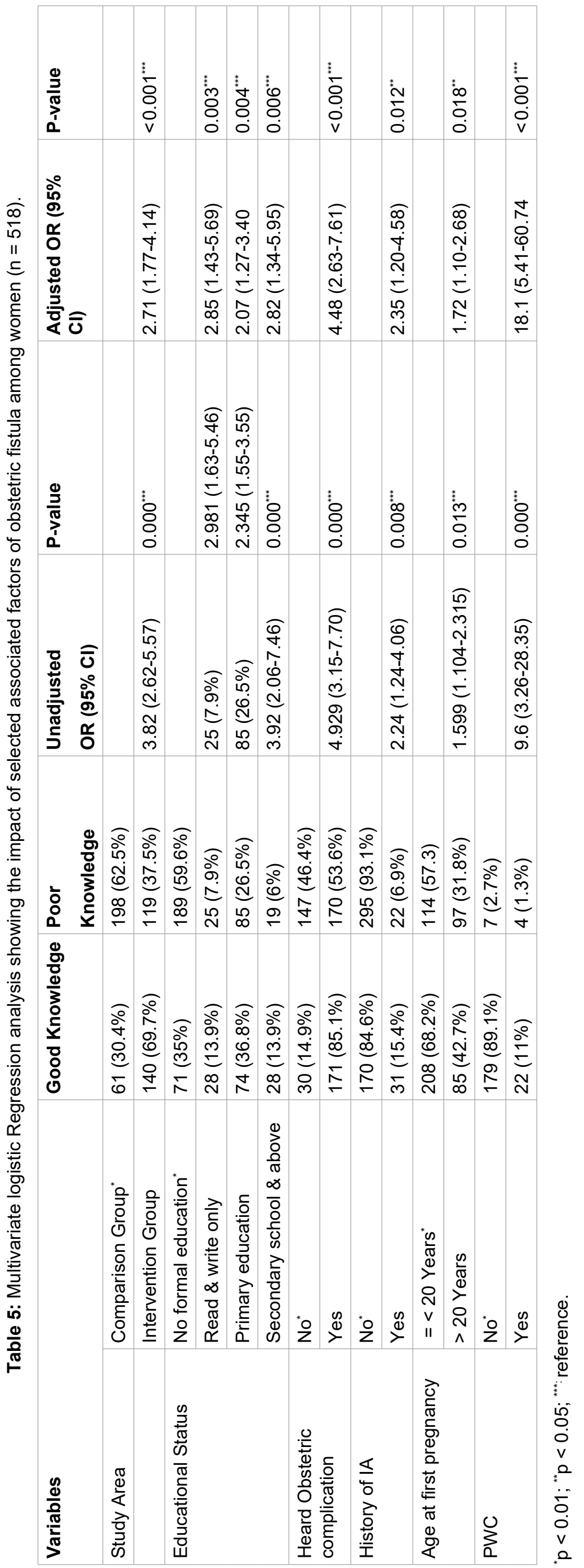

complication readiness, place of delivery and Pregnant women conference were found to have a significant association (Table 5).

In Multivariate analysis, the result showed a significant association between age at first pregnancy, pregnant women conference, heard about Obstetric complications, History of induced abortion, Educational status of women, and intervention.

Women who were from the intervention group have 2.7 times more likely to have good knowledge of Obstetric fistula compared to the comparison group $\mathrm{AOR}=2.707: 95 \% \mathrm{Cl}$ (1.7714.138)). Women who can read \& write only were 2.7 times more likely to have knowledge of Obstetrics fistula than women who have no formal education $(A O R=2.70: 95 \% \mathrm{Cl}$ (1.435.69). similarly, women who have a primary level of education were 2 times more likely to have knowledge than women who have no formal education $(A O R=2.073: 95 \% \mathrm{Cl}(1.266-3.395)$. Likewise, women who have a secondary school and above were 2.8 times more likely to have good knowledge than women who have formal education $(A O R=2.822: 95 \% \mathrm{Cl}(1.338-5.952))$.

Also, this study shows that women who heard about obstetric complications are 4.5 times more likely to have knowledge of obstetric fistula than those who haven't heard about obstetric complications $(\mathrm{AOR}=4.478: 95 \% \mathrm{Cl}$ (2.6357.610)).

Those who had a history of induced abortion were 2.4 times more likely to have good knowledge of obstetric fistula prevention than women who have no history of induced abortion $(A O R=2.347: 95 \% \mathrm{Cl}(1.203-4.576))$.

Women older than 20 years of age at first pregnancy were 1.7 times more likely to have knowledge of obstetric fistula prevention than those 20 or younger than 20 years of age at first pregnancy (AOR $=1.715: 95 \% \mathrm{Cl}(1.0979-2.679)$ ).

Women who have participated in pregnant women conferences were 18 times more likely to have good knowledge of obstetric fistula than those not participating in pregnant women conference $(A O R=9.6: 95 \% \mathrm{Cl}(3.26-28.35))$. The area under the curve (AUC) of ROC of this multivariable model was 0.80 as shown in Figure 2.

\section{Discussion}

The evaluation was a Quasi-experimental study with a Comparison Group's post-test only, aimed at outcome evaluation of fistula care project intervention on knowledge related 


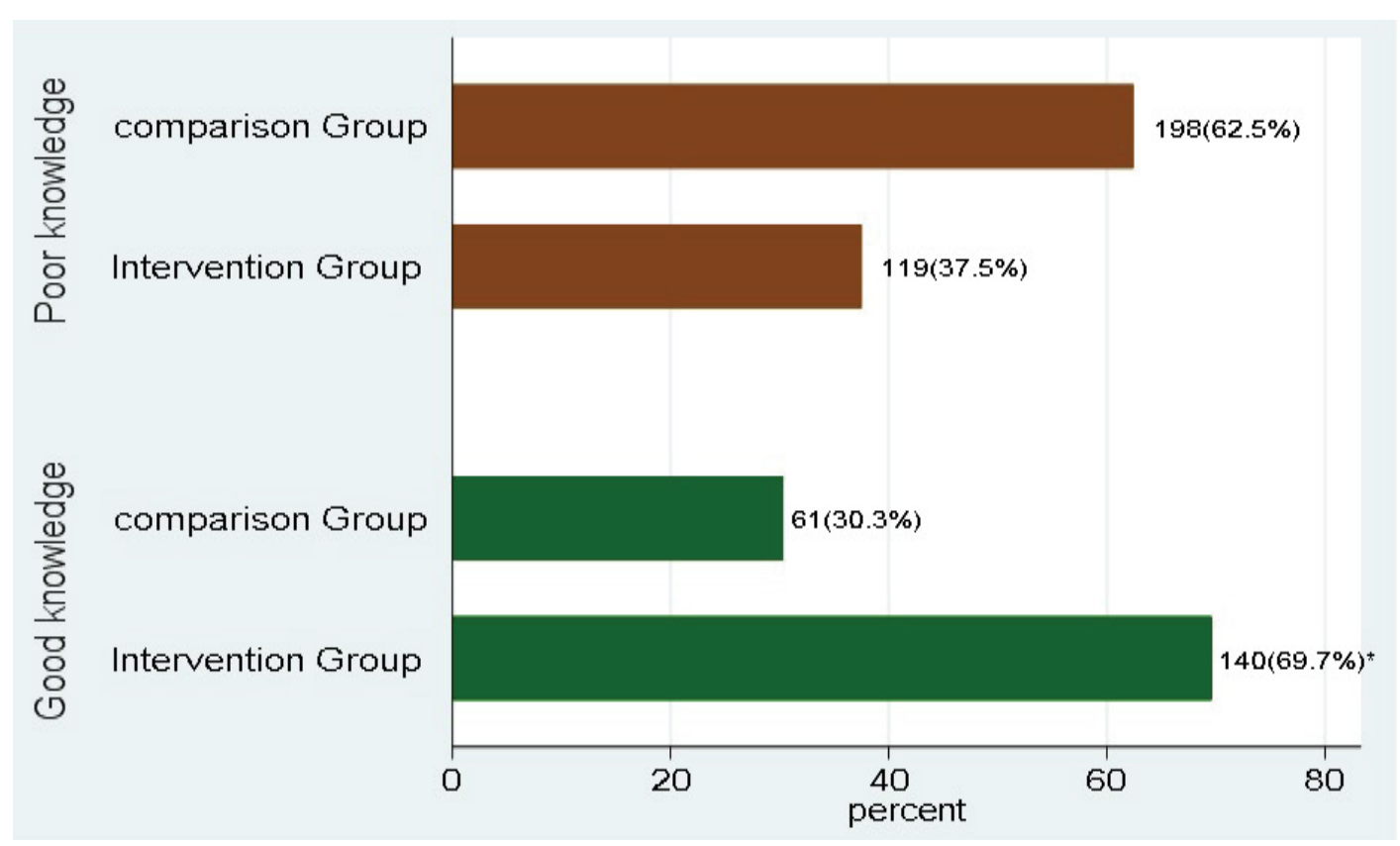

Figure 1: Overall knowledge status of women.

*: Chi-square test, $p<0.05$ is statistically significant.

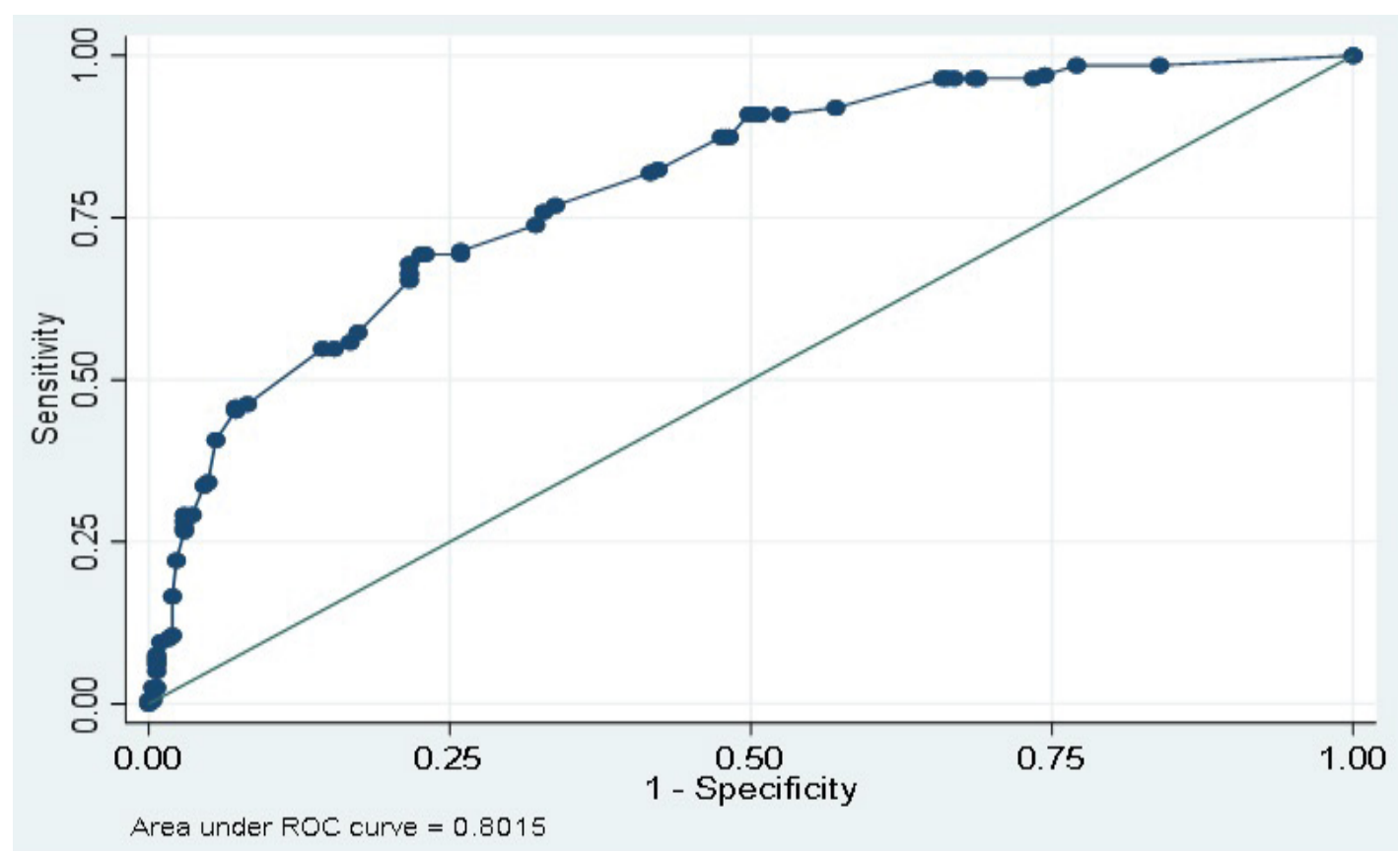

Figure 2: Receiver operating characteristic (ROC) of the suggested multivariate model.

to prevention and treatment of obstetric fistula in the Bench Sheko Zone community. This evaluation shows that women who have ever heard and describe obstetric fistula were $54.1 \%$ and $25.9 \%$ from intervention and comparison groups respectively. These finding merits attention, as considerable efforts are made in community interventions to raise knowledge of obstetric fistula related issues to describe what obstetric fistula is. This finding was higher thanthe study done in Burkina Faso which is $36 \%$ [11]. An evaluation study done in Guinea shows that $34 \%$ of women in the intervention group reported that they had heard of obstetric fistula and were able to describe what obstetric fistula is, compared with $25 \%$ of women in the comparison group [14]. The difference might be due to the sample size, and the year of the study. This result is higher than EDHS, 2016 of which 2 in 5 women interviewed in the survey had heard of obstetric fistula (39\%) [15]. This difference might be due to EDHS takes samples from different regions of Ethiopia which have different geographical locations, social and cultural factors and our study took only two woreda of Bench Sheko zone SNNPR region.

These outcome evaluation findings also underscore that women who had heard and were able to describe obstetric fistula, $49.5 \%$ of those in the intervention group 
were able to list at least one cause of the condition, compared with $18.5 \%$ in the comparison group. The majority $75.7 \%$ of the respondents from the intervention group replied Prolonged labor as cause and 57.9\% sexual violence as a cause for Obstetrics fistula. This implies that the difference may be due to participatory community interventions by a key community leader to raise knowledge of women on prolonged labor and sexual violence as the cause of obstetric fistula.

These outcome evaluation findings are consistent with the evaluation of community-level fistula prevention interventions in Guinea which show that women who had heard of and were able to describe obstetric fistula, $48 \%$ of those in intervention villages were able to list at least two cause of the condition, compared with $32 \%$ in comparison villages [14]. Similarly, a study done in Kenya shows that $53 \%$ of the respondents believed that obstetric fistula was majorly caused by pregnancy and childbirth-related complications such as prolonged labor, caesarian section, or the age of the mother [16].

This evaluation finding highlights the importance of increased attention to the risk of obstetric fistula, and among women who had heard of obstetric fistula; $46.3 \%$ from the intervention group and $15.1 \%$ from the comparison group knew at least two risk factors of obstetric fistula. The perceived risk factors for obstetric fistula from the intervention group include home delivery and Early Marriage. The possible differences in the content of the intervention provided to the intervention group may have more effect in their knowledge raising activities whether through home visits/pregnancy women conference, community meeting, or through other awareness-raising activities, such as health education talks and community discussions.

This finding is consistent with a study conducted in Ghana on Knowledge of obstetric fistula among prenatal clinic attendees which showed that perceived risk factors for obstetric fistula included home delivery $(80.5 \%)$, prolonged labor $(67.3 \%)$, teenage pregnancy and delivery (50.4\%) [17].

This outcome evaluation shows that more than half $49.8 \%$ of participants from the intervention group have listed at least two symptoms of obstetric fistula $93.6 \%, 87.1 \%, 60.7 \%$ unable to control urine, feces, and both respectively. While comparison group listed $85 \%$, $47.8 \%$, and $43.3 \%$ unable to control urine, both and feces respectively. The difference may be due to the community-based intervention to increase community knowledge on obstetric fistula symptoms.

A study conducted in Nigeria to assess the knowledge of pregnant women on Vesicovaginal fistula shows $57.8 \%$ knew Vesicovaginal fistula while $42.2 \%$ did not know about the disease [18]. This difference might be due to socio-demographic, including a diverse study population. and study area.
Our outcome evaluation shows that about half $52.1 \%$ of participants from the intervention group and $18.9 \%$ from the comparison group were able to cite one or more ways to prevent obstetric fistula. From obstetric fistula prevention methods, the intervention group was list includes delivery with a skilled birth attendant $50 \%$ and health facility delivery $50.7 \%$ and $26.9 \%$ and $29.9 \%$ from the comparison group. This implies that one of the aims of fistula care was to increase knowledge of women on ways of prevention of obstetric fistula like health facility delivery, delivery with a skilled birth attendant, so the difference may be due to intervention.

Furthermore, the present evaluation finding is lower than a similar evaluation done in Guinea which reported that $96 \%$ vs. $90 \%$ of women from the intervention and comparison group were able to list at least one way to prevent obstetric fistula [14]. This difference might be due to, study period, socio-demographic, including a diverse study population.

This outcome evaluation revealed that knowledge of women on the treatment of obstetric fistula shows that the majority $48 \%$ from the intervention group and onlya few $15 \%$ of respondents from the comparison group know that obstetric fistula can be treated.

This study was consistent with a study conducted in Ghana on Knowledge of obstetric fistula among prenatal clinic attendees on treatment for obstetric fistula show that two-thirds $66.7 \%$ of the women who knew about obstetric fistula agreed that the condition could be treated [17].

According to this outcome evaluation, the intervention effect caused a statistically significant difference in women's obstetric fistula knowledge as evidenced by the fact that respondents who received a community-based intervention had a good knowledge compared to those in the comparison group. Our outcome evaluation revealed that the overall knowledge status of women on obstetric fistula was $69.7 \%$ in the intervention group and $30.4 \%$ in the comparison group. This outcome evaluation suggests that community intervention may have a beneficial effect on women's knowledge of obstetric fistula. This finding is similar to a study done in Ghana which shows that from mothers who had heard of obstetric fistula, 37.2\% had poor knowledge, 62.8\% had good knowledge [17].

Our study shows that knowledge of obstetric fistula was higher by 2.8 times among respondents who read $\&$ write only compared to those who didn't attend formal education. Women who have a primary level of education are two times more likely to have knowledge compared to women who have no formal education. Women who have a secondary school and above were two 2.8 times more likely to have knowledge compared to women who have no formal education. This study agrees with the study done in Burkina Faso on obstetric 
fistula knowledge [11]. This might be due to those attending formal education have greater opportunities to get information, asking, and getting health services than those who hadn't attended formal education.

The findings from this evaluation suggest that women who heard about obstetric complications were 4.5 times more likely to have knowledge of obstetric fistula than those who haven't heard about obstetric complications. This might be because of the issue that obstetrics fistula can also be informed together with dangers sign of pregnancy since it is among the childbirth complications.

Mothers who had a history of induced abortion were two times more likely to have knowledge of obstetrics fistula prevention than their counter parts. This finding is lower than the study in Burkina Faso those who had no history of pregnancy were less likely to have good awareness by $80 \%$ [11].

The study identified several important determinants of the knowledge status of women on obstetric fistula. Overall, this outcome evaluation suggests that, where effective community-level intervention for obstetric fistula cause, risk, prevention, and treatment promotion existed, they had a strong and positive influence on knowledge status of women; controlling for educational status heard about obstetric complication, history of induced abortion women living in an intervention woreda were eighteen times more likely to have good knowledge of obstetric fistula than those from comparison woreda. So, this outcome evaluation of community-based intervention on women's knowledge of obstetric fistula cause, risk, symptom, and prevention shows that intervention has a significant difference when compared with the comparison group. This finding is consistent with the evaluation of a community intervention for the promotion of safe motherhood in Eritrea and Guinea which shows that women's knowledge of birth danger signs, increased significantly in the intervention group but not in the comparison group $[12,14]$.

\section{Limitations of the Evaluation}

It is very difficult to achieve in any study without drawbacks so there are possible limitations that may influence the findings while conducting this outcome evaluation; notably the lack of a comparable baseline study for analysis. While the design of the study attempted to address this issue by using a seven-year reference period.

The post-test study design does not allow for the analysis of changes since the inception of the program. Therefore, it is not possible to definitively assume causality for differences found between women in the intervention and comparison group, many of these differences may have been pre-existing.

\section{Conclusion}

We evaluated the fistula care project with a special focus on its community-based activities to improve awareness and knowledge on obstetric fistula. This outcome evaluation highlight that tailored communitybased intervention can successfully increase women's knowledge of obstetric fistula. Women in the intervention woreda gained knowledge about obstetric fistula than counterparts, almost more than half of women in the intervention group have good knowledge about obstetric fistula cause, and able to list at least two causes, risk, symptoms, prevention, and treatment of the condition.

Therefore, this outcome evaluation shows the status of women's knowledge in the comparison group indicates that giving attention to targeting the reproductive health of women in the study area is critical. Thus, a significant change was apparent in the intervention group, and show that the effects may be even greater as the intervention continues. Still, there is a gap in knowledge of obstetrics fistula; therefore, it is good to scale up the intervention on providing information on safe motherhood issues, particularly about obstetrics fistula in all woredas.

\section{Ethics Approval and Consent to Participate}

Ethical clearance was obtained from the Institutional Review Broad of the Institute of Health, Jimma University. The official letter of cooperation was written to Bench Sheko Zone Health Office for permission. The aim of the study was fully explained to the study participants to obtain their written consent before participation in the study and data was kept confidential. Written informed consent was obtained from each respondent before the interview. The evaluation was conducted as per the established time frame to safeguard the confidentiality of information obtained during the evaluation and followed to ensure the quality of the evaluation. Data collection for this evaluation was done using the local language with all consideration of the norm and values of the population in the study area.

\section{Acknowledgments}

We thank the United Nations Population Fund for financial support for carrying out this outcome evaluation thesis. Our data collection team for their hard work to conduct the surveys. We thank Bench Sheko Zone health Department, Semen bench, and Guraferda woreda health officials, for their invaluable support in the process of the data collection.

\section{Funding}

This evaluation was supported by financial assistance from UNFPA. This funding organization covered the processes of data collection.

\section{References}


1. Tunçalp O, Tripathi V, Landry E, Stanton CK, Ahmed S (2017) Measuring the incidence and prevalence of obstetric fistula: Approaches, needs, and recommendations. Bull World Health Organ 93.

2. WHO (2018) Obstetric fistula.

3. Hamlin Fistula USA (2015) Obstetric Fistula in the United States.

4. Tebeu PM, Fomulu JN, Khaddaj S, De Bernis L, Delvaux T, et al. (2012) Risk factors for obstetric fistula : A clinical review. Int Urogynecol J 23: 387-394.

5. UNFPA (2019) Obstetric fistula.

6. Nolsøe CP (2013) Campaign to End Fistula with special focus on Ethiopia - A walk to beautiful 1 Is there a role for an ultrasound? Australas J Ultrasound Med 16: 45-55.

7. Baker Z, Bellows B, Bach R, Warren C (2017) Barriers to obstetric fistula treatment in low-income countries: A systematic review. Trop Med Int Heal 22: 938-959.

8. FMOH (2015) Strategic Plan Elimination of Obstetric Fistula in Ethiopia by the 2020 Strategic Plan for Elimination of Obstetric Fistula in Ethiopia by 2020 Federal Ministry of Health.

9. WHO (2006) Obstetric Fistula Guideline.

10. Yenipinar A, Seyma KOC, Canga D, Kaya F (2019) Determining sample size in logistic regression with G-Power. BS Publishers.
11. Banke-Thomas AO, Kouraogo SF, Siribie A, Taddese HB, Mueller JE (2013) Knowledge of obstetric fistula prevention amongst young women in urban and rural Burkina Faso: A cross-sectional study. PLoS One 8: 1-8.

12. Turan JM, Tesfagiorghis M, Polan ML (2011) Evaluation of a community intervention for promotion of safe motherhood in Eritrea. J Midwifery Women's Heal 56: 8-17.

13. Feyisa WB, Nigusie AA, Yenealem FB (2019) Awareness and its associated factors of obstetrics fistula among pregnant mothers attending antenatal care clinics. Matern Fetal Med 21203.

14. Interventions CFP (2013) Fistula Care. Guinea fistula care program evaluation.

15. Central Statistical Agency (CSA), ICF (2017) Demographic and Health Survey 2016. Ethiopia.

16. Mogambi H (2016) Moving health forward: Communication and elimination of Obstetric Fistula in Kenya. IOSR Journal Of Humanities And Social Science 21: 67-80.

17. Azanu WK, Dassah ET, Agbeno EK, Ofori AA, Opare-Addo HS (2020) Knowledge of obstetric fistula among prenatal clinic attendees and midwives in Mfantsiman municipality, Ghana. Int J Gynecol Obstet 148: 16-21.

18. Ezeonu PO, Ekwedigwe KC, Isikhuemen ME, Eliboh MO, Onoh RC, et al. (2017) Awareness of obstetric vesicovaginal fistula among pregnant women in a Rural Hospital. Adv Reprod Sci 05: 39-46. 